\title{
SURVIVAL IN PATIENTS WITH STAGE IV HER2 POSITIVE BREAST CANCER
}

Marcelo A. Bello1, Marcelo M. Barbosa', Marcela E. Carvalho', Sergio Monteiro', Patricia Juca', Anke Bergmann¹

${ }^{1}$ Hospital do Câncer III, Instituto Nacional de Câncer - Rio de Janeiro (RJ), Brazil.

Objective: To evaluate the survival of patients with metastatic breast tumors, with human epidermal growth factor (HER2) receptors, present and treated in Unit 3 of the National Cancer Institute. Methodology: Retrospective cohort study with women diagnosed and treated in Unit 3 of the National Cancer Institute, in the years 2008 and 2009 (n=2035). For this analysis, patients with HER2 positive at diagnosis, clinical staging I to III $(\mathrm{n}=412)$ and who progressed with metastasis in the follow-up period ( $\mathrm{n}=92$ ) were selected. In this group of patients, $15.2 \%$ did herceptin palliative and $84.8 \%$ did not. Results: Among the 92 positive Herb 2 patients who progressed with distant metastasis, $32.6 \%$ had bone or soft tissue, $62 \%$ visceral and 5.4\% locoregional metastasis, respectively. The mean survival of the patients was 38.4 months. Among those taking Herceptin, the mean survival was 49.7 months, while those who did not were 35.9 months. Among 31 patients with bone metastasis, enrolled between 2007 and 2009, 5 (16\%) did Herceptin and 31 (84\%) did not. The mean survival was 51.3 months and 31.7 months, respectively. In general, those patients who did not take Herceptin had a 2.35-fold higher risk of death compared to those who $\operatorname{did}(\mathrm{HR}=2.3595 \% \mathrm{CI} 1.12-4.95, \mathrm{p}=0.024)$. Conclusion: The use of trastuzumab in the palliative treatment of Herb2 positive patients had an impact on survival in the present study, including isolated bone metastases. 